\title{
RADIUM RAYS AND PLANT LIFE PROCESSES.*
}

\author{
SOMEINTERESTING DISCOVERIES.
}

\section{BY PROF C. STUART GAGER, UNIVERSITY OF MISSOURI.}

Ovr interest in the effects of radium rays on living organisms is enhanced by the discovery that radioactivity is widely distributed in nature. It is probable that all plants and animals are adjusted to a norma degree of radioactivity in their environment, or, in other words, are in a state of radiotonus. Prof. J. J. Thomson was the first to discover that air bubbled through Cambridge (England) tap-water became decidedly radioactive, and the subsequent researches of numerous other physicists have taught us that this property belongs to the waters of most deep wells, to mineral waters generally, to freshly fallen rain or snow, to the spray at the foot of waterfalls, to the water of the ocean in certain localities, and quite probably to all spring waters. degree of activity of the preparations in terms of the activity of uranium taken as a unit. Radium bromide of $1,800,000$ activity is the purest salt thus far obtained. The lower right-hand tube contains radiotellurium, which gives off only a rays.

The rod below the tubes is of celluloid, coated on one end with radium bromide of 25,000 activity. The radium coating is overlaid with one of celloidin for purposes of protection.

By means of the rod, not only the three kinds of rays, but the emanation as well, are available. The walls of the sealed glass tubes permit the $\beta$ and $\gamma$ rays to pass, but the emanation and the a rays not at all.

Radium coatings, such as those on the rod, were
Germination is easily retarded or inhibited by exposing seeds while dry, or during imbibition of water. In one experiment ten seeds of "Lincoln" oats, after being soaked in water over night, were exposed for eighteen hours to rays from the tube of 10,000 activity, by being placed with their embryo-sides in contact with the tube Germination was retarded by this treatment. After being exposed for about 50 hours longer to the same preparation ( 67 hours 35 minutes in all), the seeds, together with ten unexposed, but otherwise similarly treated seeds, were planted in soil in pots. The relative amount of growth in the two the end of five days after planting is illustrated in Fig. 2, where $R$ is the culture exposed to the rays, and $C$ the control (unexposed) culture. The

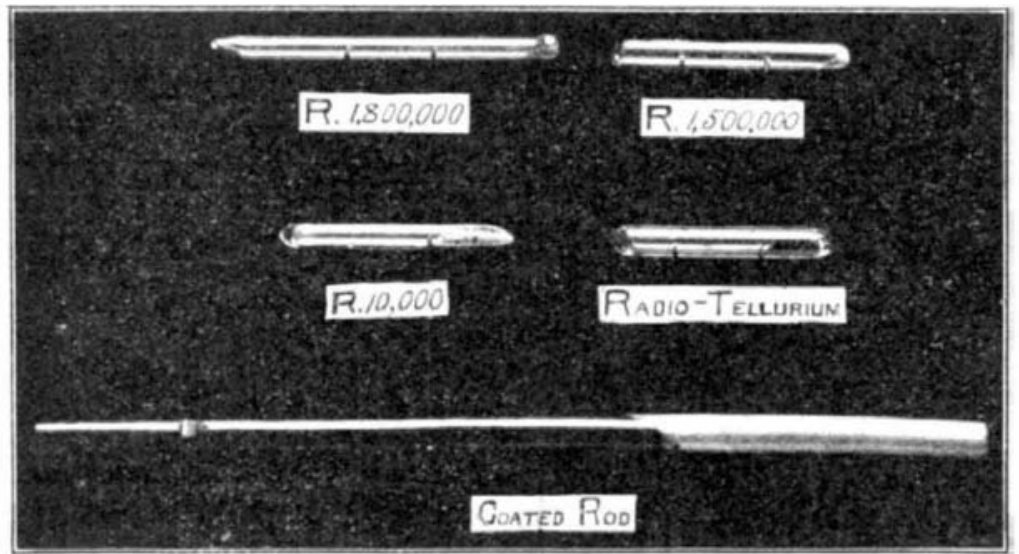

FIG. 1.-SOME OF THE PREPARATIONS EMPLOYED.

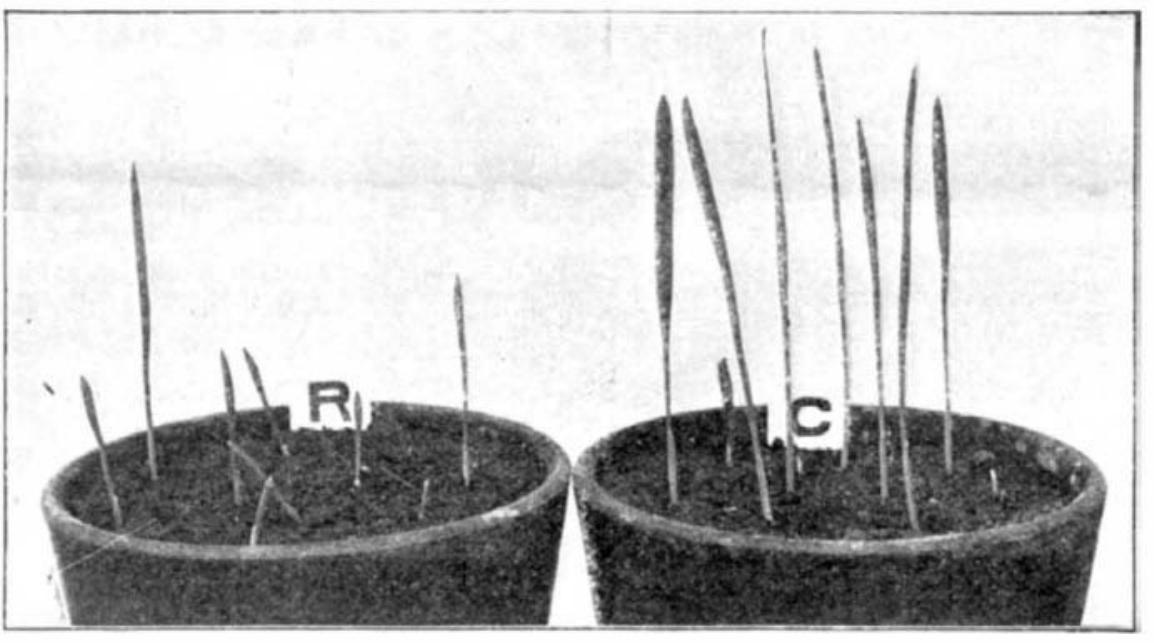

Fig. 2.-SHOWING THE EFFECT ON GERMINATION.

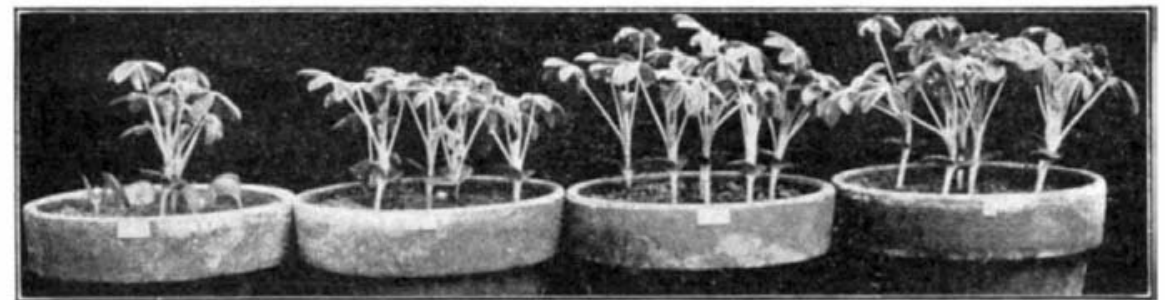

FIG, 3.-EFFECT OF RADIUM ON THE GROWTH OF LUPINES,

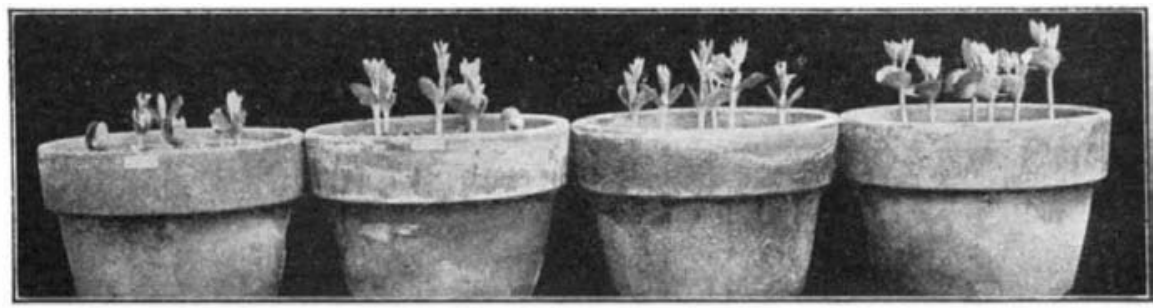

Fia. 4.-RELATIVE EFFECT OF PREPARATIONS OF DIFFERENT AC'IIVITIES.

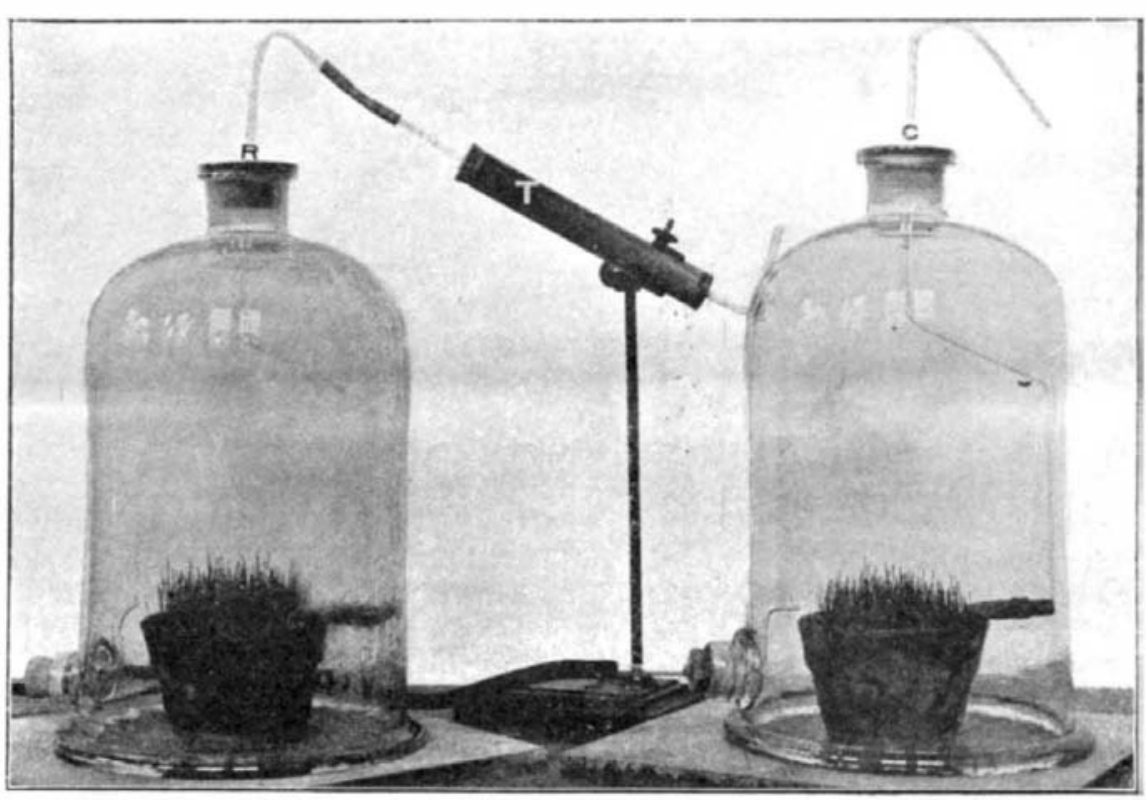

FIG. 5.-LIEBER TUBE.

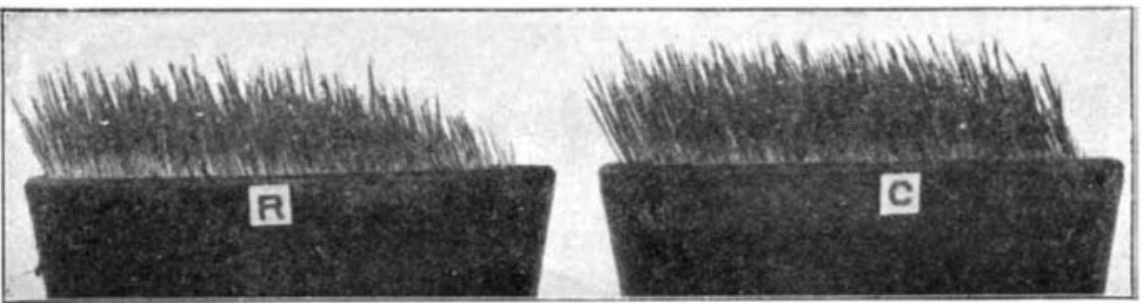

Fig. 6.-EFFECT OF RADIOACTIVE AIR
After Elster and Geitel found radioactivity a property of the "fango," or mud from the hot springs of Battaglia, in northern Italy, other investigators discovered the same property in mud from various widely separated sources, in lava from volcanoes, in the sediments of springs, the sand of the seashore, and in sedimentary rocks.

The discovery, also made by Elster and Geitel, of the presence of radioactivity in the earth's atmosphere has been abundantly confirmed. Soil-air is more strongly radioactive than air above the surface. Evidence leads to the conclusion that the radioactivity of water, air, mud, rocks, etc., is due to the presence of the emanation of radium and other radioactive substances.

Radioactivity, therefore, must be recognized as a factor of plant environment, and plant physiology and the newer physics join hands. Here, as elsewhere, the boundaries between the different "sciences" break down

Fig. 1 is from a photograph of a few of the preparations employed in the experiments about to be described. The three marked $R$ are sealed glass tubes containing radium bromide. The figures indicate the * Contributions from the Botanical Department of the University of Nissouri, No. 16. Abstracted from Popular Science Monthly. devised by Mr. Hugo Lieber, of New York city, and are a valuable aid in studying the physiological rôle of radium. The experiments of the writer, carried on for over three years at the New York Botanica Garden, were made possible solely through the great liberality of $\mathrm{Mr}$. Lieber, who freely supplied all the standard preparations, several thousand dollars worth in all.

In none of the experiments did the radium itself come in contact with the plant tissues. The result noted were due to the action of the rays alone. When the sealed glass tubes were used, the effect was produced by the $\beta$ and $\gamma$ rays, acting together; when the radium coatings were employed, by the combined action of the emanation and the rays, $a, \beta$, and $\gamma$

To review the results obtained by other investigators is beyond the scope and purpose of the present article. Koernicke, Dixon and Wighman, A. B. Greene, Guilleminot, and Abbe, not to mention others, have experimented on the action of radium rays on germination and growth, and, to a slight extent, upon other plant processes. There seems to be general agreement among them that the rays exert a retarding or an in hibiting effect, depending upon the activity of the preparation employed and the duration of exposure to the rays. growth of the root system was also greatly retarded by this treatment, and the root hairs on seedlings from exposed seeds were much longer than normally. The effect of duration of exposure on the germination and growth of lupines (Lupinus albus) is shown in Fig. 3. The activity of the radium was the same in each case, $1,800,000$, the seeds were exposed dry, and the length of exposure, from left to right in the figure, was 72 hours, 50 hours, 26 hours, 0 hours (control). The size of the largest seedling in the pan at the left doubtless indicates that the seed was poorly exposed, There is usually more or less difference in the resistance of individuals, but never as much as that apparently indicated, in the 72-hour culture. This and similar experiments confirm the results of Koernicke and others that the effect varies directly with the duration of exposure.

The relative effect of preparations of different activities is illustrated by the following typical experiment. Three sets, $a, b$, and $c$, of six dry seeds of the white lupine were exposed to rays from sealed glass tubes of radium bromide by laying the tubes in contact with the hilum edges. of the seeds. Care was taken to have the radium salt distributed evenly along the bottom of the horizontally placed tube. The activities of the preparations were; $a, 1,800,000 ; b, 1,500,000 ; c, 10,000$. 
A fourth set, $d$, served as a control. All exposures were for 91.5 hours. The seeds were then sown in soil in pots, and the comparative amounts of growth in the four cultures are shown in Fig. 4. The activ ity decreased from left to right. It is clearly demonstrated that the stronger the activity the greater the amount of retardation, under the conditions of the experiment

An experiment to test the effect of a radioactive atmosphere on germination and growth was facilitated by the preparation by Mr. Lieber of a tube lined with the radium coating devised by him. This tube $(T$, Fig. 5) was connected with the upper tubulure of a glass bell-jar, resting air tight on a ground-glass plate. The lower tubulure was connected with an exhaust, so that air, entering the radium-lined cylinder, carried anation. This air was delivered over pots of growing plants or freshly planted seeds in various ways, one of which is shown in Fig. 5, where the radioactive air passed over the soil-surface from an ordinary dovetail gas burner. The opening to the outlet pipe is under the flower pot. A control apparatus was similarly arranged, with the exception of the omission of the radium preparation. In one experiment, after a six days' exposure of timothy grass seed, sown unsoaked and covered with only an extremely thin layer of soll, germination and growth were shown to be retarded and the amount of retardation was greatest nearest the point of dellvery of the radioactive air (Fig. 6). But where germinated seeds of the white lupine, with radicles marked 10 millimeters back from the root-tip, were exposed for twelve hours in the radioactive atmosphere, growth was greater than that of a like number of roots similarly placed in the con trol jar. In one experiment, for example, the total trol jar. In one experiment, millimeters, and for the control radicles only 16.08 millimeters.

Thus it is seen that exposure to radium rays, though followed in some cases by a retardation or in hibition of function, may, under certain suitable conditions of exposure and with certain tissues, be followed by an acceleration.

Excitation of function is further illustrated by the following experiment: In a flower pot of soil un soaked seeds of oat were sown in three concentric hours the seedlings from the exposed seeds were much taller than those in the control pot (Fig. 7), the amount of stimulation being greatest in the outer circle of plants and least in the inner circle. At the end of the 106-hour period the radium tube was placed in the control pot and the empty glass tube in the pot $R$. Following this change the seedlings in $C R$ grew faster than those in $R$, now serving as a control. Thus it was possible to accelerate the growth of the more translucent, gave the darkest image on the velox paper (Fig. 10).

It was found possible to increase the rate of respiration of germinating seeds by means of the rays, and alcoholic fermentation was also accelerated by suitable exposure, as follows: Five fermentation tubes were filled with equal quantities of a mixture of 2 grammes of a compressed yeast cake in 250 cubic

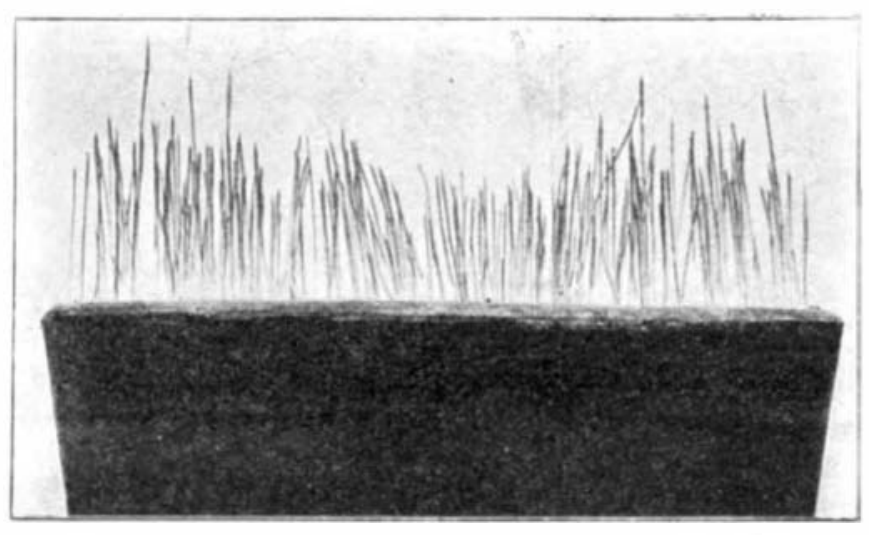

Frg. 9.-THE RADIOACTIVE EEFECT OF THE GAS MANTLE.

seedlings in either pot at will by transferring the radium tube from one culture to the other.

The fact that incandescent gas mantles contain a large percentage of thorium, a radioactive substance, suggested the following experiment. On the surface of soil in a pot was sown a row of timothy grass seed, and over this row and at right angles to it was suspended a fresh, unburned mantle at a distance of three to four millimeters above the seeds (Fig. 8). Germination and subsequent growth were both re tarded by the rays from the mantle, and Fig. 9 shows the appearance of the culture seven days after the experiment was started.

The influence of radium rayg on thotosynthesis wa tested in several ways. For example: A nasturtium (Tropceilum) plant was placed in sunlight after having been in darkness for 18 hours. Under one of the leaves, and lightly in contact with it, was placed a Lieber's coated rod of undetermined (probably 25,000 )
Into four of the fermentation tubes were placed sealed glass tubes as follows: $\operatorname{RaBr}_{2} 1,500,000 \times ; 10,000 \times$; $7,000 \times$; radio-tellurium. The fifth served as a control. At the end of about three and one-half hours the cultures were photographed (Fig. 11). It is clearly shown in the figure that the rate of alcoholic fermentation, measured by the evolution of gas, was accelerated by the rays; most by the preparation of $1,500,000$ activity, least by that of 7,000 activity, and to an immediate degree by the other preparations.

Various attempts have been made to detect a tropistic response, or curvature of a growing organ toward or from a radioactive source. The phosphorescent light of radium has not been found intense enough to call forth phototropic curvatures, and the existence of a true radiotropism is yet to be demonstrated. Koernicke found that seedlings grown from exposied seeds were still sensitive to gravity and unilateral illumination, and the experiments of the writer con-

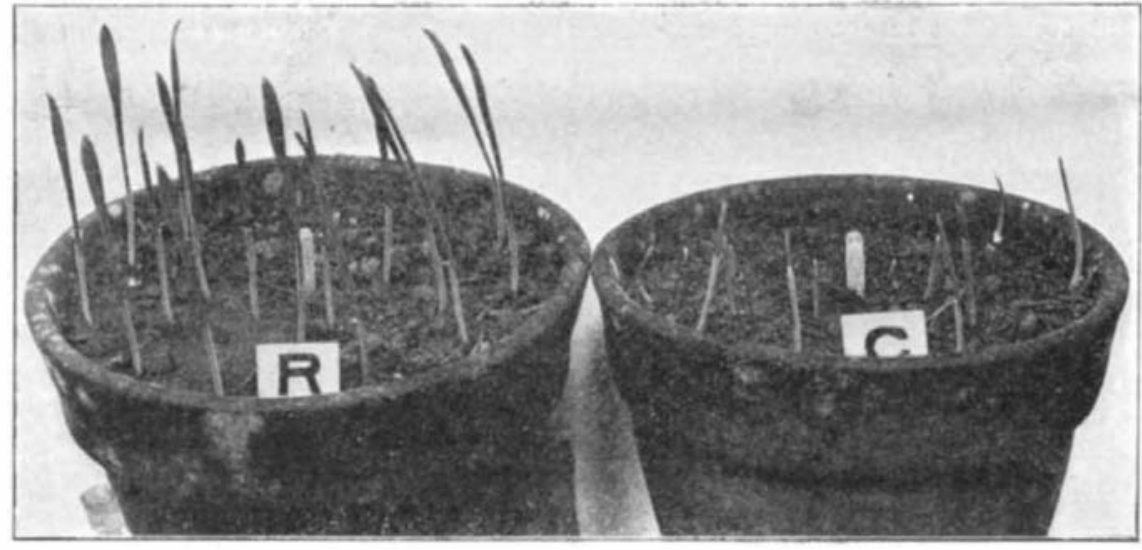

Fig. 7.-EXCITATION OF FUNCTION.

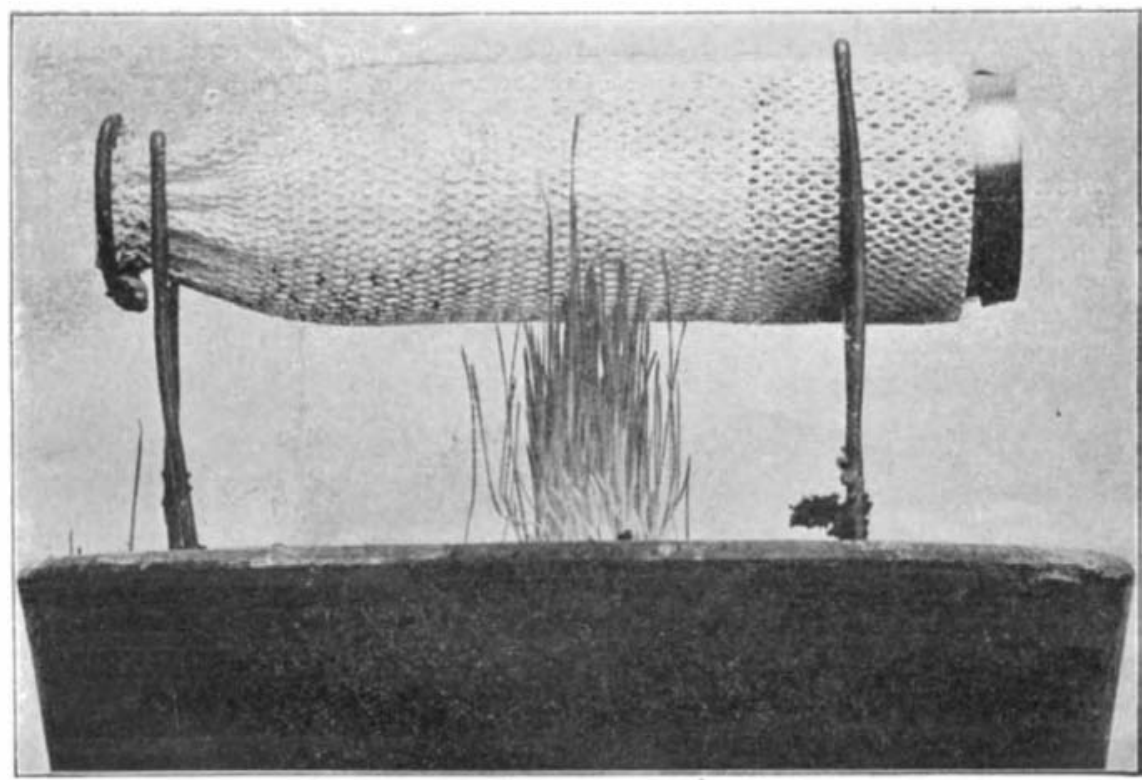

Fig. 8-AN INCANDESCENT gas MANTLE AS A RETARDER.

circles, distant, respectively, 7 millimeters, 22 millimeters, and 45 millimeters from the center of the pot. Into the soil at the center was inserted the sealed glass tube of radium bromide of $1,500,000$ activity. The end containing the radium was about 15 millimeters below the soil surface. A second pot was arranged in a like manner except for the substitution of an empty glass tube for the radium tube. At the end of 106

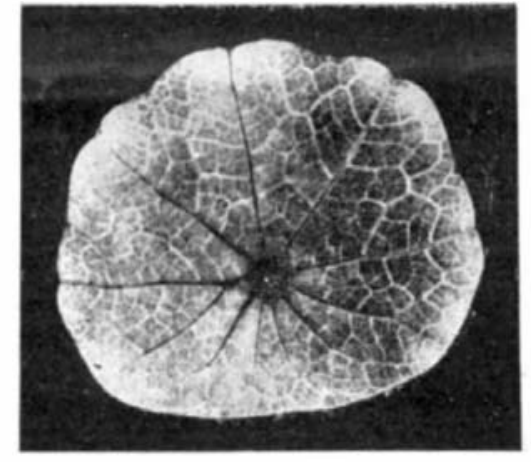

FIG. 10.-PHOTOSFNTHETIC EEFECT.
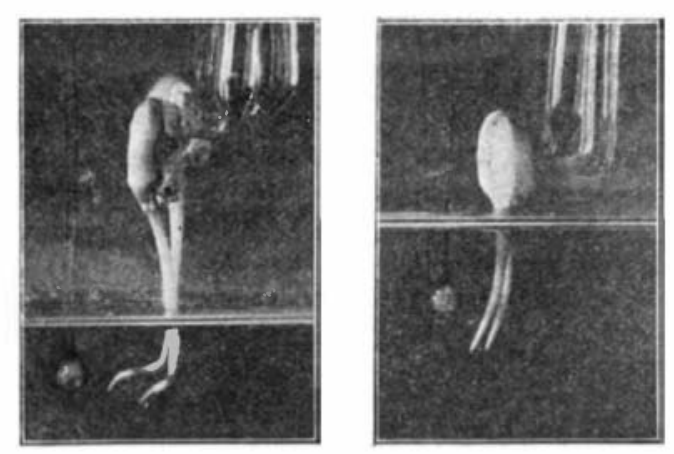

Fig. 13.-EFFECT OF RADIUM ON GROWING ORGANISMS.

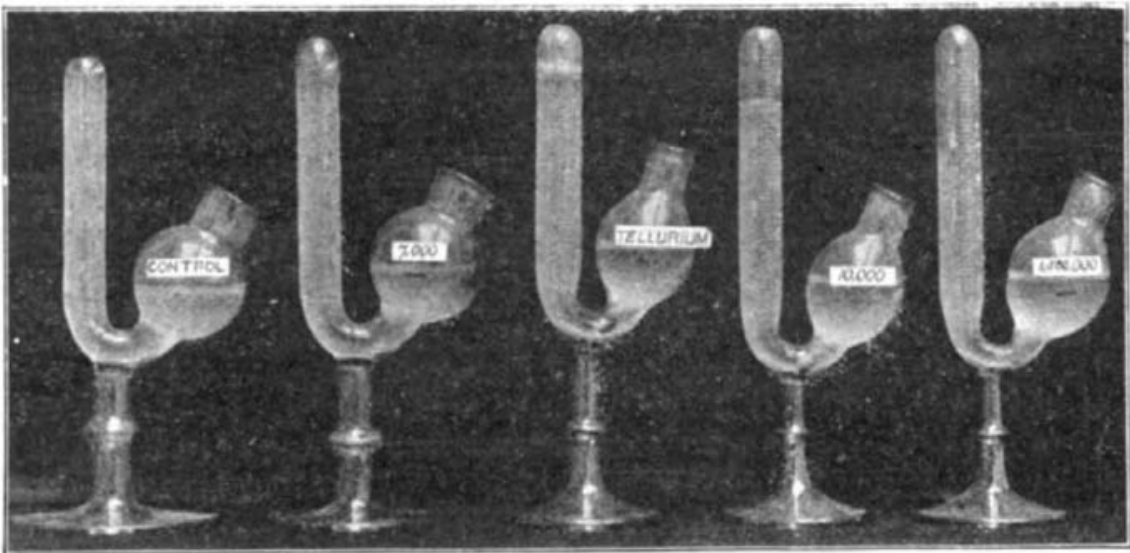

Fig. 11.-INCREASing the rate of alCoholic Fermentation.

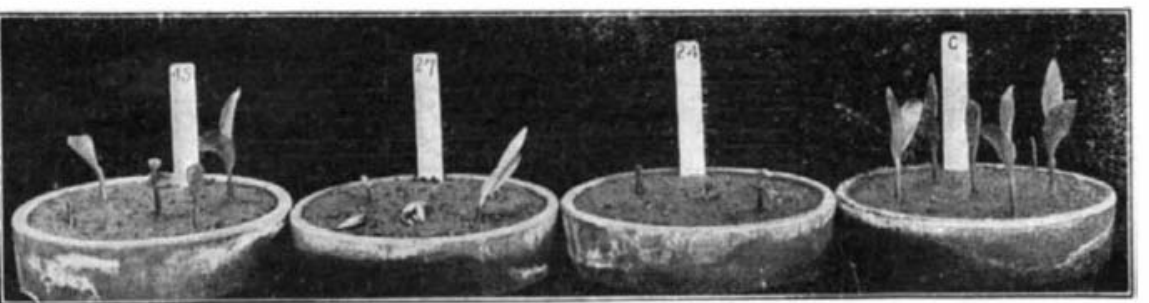

FIG. 12,-EXPERIMENT TO DISCOVER EFFECT OF RADIUM ON DIRECTION OF GROWTH.

activity. After twenty-four hours the leaf was dechlorophylized and stained with iodine to test the presence of starch. Starch was almost entirely wanting in the part of the leaf that was directly over the radium-coated rod, but was present in other portions of the leaf. The result was recorded by exposing the leaf to sunlight in contact with the velox paper in a printing frame. The region lacking starch, being firm this result. Under certain conditions of exposure of corn grains, however, the seedlings failed to respond to gravity, and grew horizontally, close to the soil surface. Thus, in one experiment, he grains were exposed for twenty-seven hours to :ays from radium bromide of $1,800,000$ activity, and all of them showed this tendency to a greater or less degree (Fig. 12 , pot 27), Whether geotropic sensibility was de- 
Stroyed by the exposure is difficult to say, for histological examination showed the tissues to be so abnormal that it is possible the plants could not have stood erect even if they had been able to detect the stimulus of gravity.

All attempts to obtain a curvature of growing organs or plants toward or from a radium tube or radium. coated rod proved unsuccessful, but when a sealed glass tube of radium bromide is suspended horizontally in tap-water, or in nutrient solution, in which radicles of white lupine seedlings are growing verti- cally, the tips of the roots may be made to curve toward the radium. Such a result is illustrated in Fig. 13. In this experiment the radium tube was originally about 5 millimeters distant from the roottips. Whether this result was due to the direct infiuence of the rays, or to some undetermined condition established by them in the liquid can not yet be decided.

The above experiments were all confirmed by repetitions, and clearly indicate that radium rays act as a stimulus to the various physiological processes of plants. If the strength of the radium, the duration of exposure, and other conditions are suitable, the response is an excitation of function, but if the method of treatment is otherwise, the radium too strong, the exposure too prolonged, the result is a retardation, or complete inhibition of function, or the death of the plant. There are not only differences in sensitiveness between individuals, but also between different species and different tissues. As in the case of animals, embryonic and younger tissues are more sensitive than those that are older and more mature.

\title{
ARTIFICIAL GEMS PAST AND PRESENT.
}

\author{
IMITATING NATURE IN THE LABORATORY.
}

\section{B Y E M I L F R E U N D.}

PuINY mentions the imitation of jewels by glass fluxes, and it is sufficiently proved that the ancients were far advanced in this art. Egyptian mummies are provided with glass buttons of green and blue color. During the Roman Empire the use of colored glass was very general. Antique cameos have been found carved in varicolored glass to represent the onyx. Colored glass was also cemented with real onyx, but the combination was never so perfect as to defy detection by the artist and jeweler.

Before dealing with the production of imitation and artificial precious stones, another distinction in terms may be made for convenience, a distinction between the words "imitation" and "artificial." To many this may appear unnecessary, the two terms being more or less synonymous. With the advance of scientific research the chemist can now make in the laboratory not merely glass imitations, but real stones artificially, which are identical in composition with those found in nature. Their artificial production is quite modern carrying us back only a generation or two. Imitation stones, however, were known in the Middle Ages, if not earlier. They were certainly known to the alchemists; for St. Thomas Aquinas mentions imitation jacinth, sapphire, emerald, topaz, and ruby. In the middle of the seventeenth century pastes were not manufactured according to a different formula for each stone as had formerly been the case, but according to one general formula, much the same as that in use at the present time. Artificial precious stones are again present time. Artificial precious stones are again ed stones, properly speaking, whether they are made scientifically or synthetically.

The first precious stone which artificially reproduced not only the appearance but also the characteristics of a natural stone was lapis lazuli, the sapphire of the ancients, which is not to be confounded with the sap. phire of our modern jewelers. This untransparent stone of a magnificent azure blue color, was most highly prized by the ancient Hindoos, Assyrians, Persians, Jews, Egyptians, Greeks, etc., and this irrefragably refutes the erroneous theory of some archaeologists that the ancients were unable to distinguish the blue color.

$$
\text { PAstes. }
$$

The basis of paste imitations is a fine, pure, and white glass composition, called "strass," after its inventor, Strass of Strassburg, in the seventeenth century, who first conceived the importance of imitating the real gems as respects their hardness, specific gravity, and refraction of light. He accomplished the task so admirably that in many instances, either all three, or one or the other of his objects, were attained. The or one or the other of his objects, were attained. The
strass is composed of silicon, potash, borax, red lead, and sometimes arsenic.

For imitating colored gems, various colored ingredients are employed. To obtain that intensity of color approaching nearest to the original gem experience alone can guide the manufacturer. In order to imitate the uniform and intense colors, the strass coloring ingredients must be finely divided or powdered, and very intimately mixed. The mass is then to be exposed to a very great heat, and in that state left for nearly thirty hours, so that the cooling may be gradual. M. Feil of Paris was one of the first men to produce a good quality of strass, and as a result imitations are now made so well that their detection is exceedingly difficult.

\section{DOUBLETS.}

Imitating real gems by "doubling" takes place when quartz cut and polished is cemented by means of gum mastic to colored paste, whereby the whole stone assumes the color of the lower paste. When a real gem is employed instead of quartz (the surface and the quartz or paste being cemented below) the process is called "half doubling." This adulteration is carried on to a very great extent in the East Indies, where any thin gem is joined to a paste of corresponding color.
The concave doubling is effected by excavating the inside of a quartz or paste. This cavity being fllled by a colored fluid, and the other part afterward cemented on it, will, when well executed, present so uniform a color that it is difficult even for a judge to detect the deception. The surest method of detection is to put the specimen in question in hot water or alcohol, so that the gilm mastic will be dissolved. When set, the only way of discovering the adulteration is to put it reversely on the nail of the thumb, when the false refraction of light or the rainbow colors will surely re veal its identity.

\section{BURNING.}

This mode of adulterating the real gems by coloring cut and polished quartz specimens and throwing them into a solution of permanent pigments, such as indigo cochineal, or ammoniacal copper, the small cavities produced by the heat will absorb the fluids. The topa is burnt by itself, with or without the absorption of pigment, as also spinel and quartz. Chalcedony is, however, frequently burnt to imitate onyx, and to engrave thereon cameos and intaglios. It may be remarked, however, that since the introduction of colored pastes very few adulterations of this kind are practised and we see such doublets and burnt stones but rarely. ARTIFICIAL GEMS.

Artificial gems are at present of considerable inter'est and furnish an example of the strides made by modern chemistry. In 1886 there appeared in the Paris market certain stones which had been offered for sale by a Geneva house as rubies from a new locality; subsequently, it was said that they were obtained by the fusion of a large number of small rubies, worth a most but a few dollars a carat, into one gem worth many times that amount. An examination proved that they were not the product of a fusion, which would have resulted in the formation of a substance lower in its specific gravity and softer than a ruby. They were artificial stones and had been formed by heat, not from rubies, but evidently by passing an aluminate of lead in connection with silica into a siliceous crucible, the silica uniting with the lead to form a lead silicate and liberating the aluminate, which crystallized in the form of corundum. The difference between these stones and the true ruby was very apparent, owing to the presence of a large number of spherical bubbles, some pear-shaped, and a stringy in ternal structure, showing how bubbles had moved. $\mathrm{Mr}$. Ebelman, at Sevres, over sixty years ago, and $\mathrm{Mr}$. Fremy of Paris, after years experimenting has with the assistance of M. Verneuil succeeded in obtainin large numbers of beautiful crystals, but only after many experiments, and conditioned largely upon the heat, which regulates chemical action. Though the color is excellent, the crystals do not exceed 1/25 to $1 / 50$ of an inch in diameter.

Several decades ago the chemist Gaudin succeeded in obtaining small ruby pellets from pure argillaceous earth, precipitated from dissolved alum and moistened with chromate of potash. The color of these rubies, according to the quantity of chromate which they contained was either that of a rose or bordering purple. The pellets were so hard that they easily cut glass, garnets, and topazes, but they were not crystals and their transparency was by no means perfect. Similar experiments were made by the chemists De Bray, Sainte Claire Deville, Caren Senarmont, Ebelman, and others. "Reconstructed" rubies are obtained by melting together or fusing small rubies of inferior quality with quartz of the same hardness and specific gravity. They came to America in 1886 and were sold as high as $\$ 80, \$ 100$, to $\$ 150$ per carat. Others again were sold for $\$ 20$, $\$ 10$, etc. Again others could not be used as gems and were even not good enough for mechanical purposes. The inventor of the reconstructed rubies was a Catholic priest who lived in seclusion near Geneva. He furnished this reconstruction rough to a lapidary firm of that city, who introduced the same to the trade. With his death the formula, which was a secret, was lost Never since have better rubies been produced. A few can still be found in the handy of gem lovers.

In 1889 a well-known American firm imported an artificial ruby called a "scientific ruby." This ruby was built up or fused together out of small inferior rubies and later split and polished. These stones were all cut in the old Indian cut and after they came to New York they were assorted according to their quality and then recut in the modern style. These scientific rubies were examined by the Columbia School of Mines, and the test showed that they were fused from natural rubies. Only their hardness showed that they were harder than the genuine stone, while the specific gravity, the optical and chemical properties were those of the natural ruby. These rubies were sold from $\$ 60$ to $\$ 150$ per carat, none less than $\$ 60$.

These stones were all of fine color and good quality. Reconstructed rubies, on the other hand, are sometimes brownish and resemble garnets. It was rather difficult for an expert to recognize them at first glance. The stones had the same inclusions as the natural ruby. Through competition these rubies were sold cheaply and now none as good are made. These scientific rubies were a puzzle to the lapidaries. It was in their favor that they were crystallized, while this was not the case with the reconstructed. The rubies sold what they pretend to be. Th€y are all artiflcial rubies and ought to be called so.

It is reported that as a result of numerous experiments certain French chemists have at length succeeded in discovering a new method of producing artificial rubies, which is more practical and considerably cheaper than the ordinary process. The "machine" constructed for the manufacture of rubies is provided with a blowpipe similar to a glass blower's pipe and a heating pipe. In the latter are sifted finely-pulverized alumina and chromium oxides alternately to form a deposit in strata and in the shape of a conical sugarloaf. This formation makes gradual heating possible. The mass assumes a spherical form, and on hardening the crystalline character of the ruby appears. Great care is taken to let the mass cool slowly in order that the formation of crystals shall be regular and the stones clear, the formation of bubbles being sedulously guarded against.

With this simple apparatus three or four rubies are made at a time, and they can be distinguished from natural mechanically cut rubies only by skilled experts. The artificial ruby can readily be distinguished from the natural by examination under the microscope. The natural gem contains minute cracks, as seen with the microscope. Even though it seems to be entirely flawless, careful examination with the microscope of 100 diameters will show minute cleavage cracks running through the gem. The artificial gem contains nothing of this sort, but shows very minute bubbles or gas holes. So far as the luster and hardness are concerned, the artificial stone is exactly like the natural, and no one could tell the difference, except by this microscopic test.

Small artificial stones are made after an invention of Boettger of the same material as the genuine, chiefly alumina. The hydrate of alumina is precipitated from the solution of an alumina salt, by means of an alkali; then well washed and mixed with nickel salt, and rolled into small sticks about the thickness of a finger. Any cracks formed during drying must be filled with the same material. When dry, the end of such a stick is held in the intensely hot flame of an oxy-hydrogen blowpipe, whereupon globules are melted off, among which some will be so hard as not only to scratch glass, but even quartz, topaz, and granite. These are then cut and polished like gems. When nickel salts are used the emerald is obtained. For rubies, chromate of potash is used. They may be 